\title{
BMJ Global Health Causes of severe visual impairment and blindness in students in schools for the blind in Northwest Ethiopia
}

\author{
Mulusew Asferaw, ${ }^{1}$ Geoffrey Woodruff, ${ }^{2}$ Clare Gilbert $^{3}$
}

To cite: Asferaw M, Woodruff G, Gilbert C. Causes of severe visual impairment and blindness in students in schools for the blind in Northwest Ethiopia. BMJ Glob Health 2017;2:e000264. doi:10.1136/ bmjgh-2016-000264

Received 5 December 2016 Revised 17 March 2017 Accepted 20 March 2017

\section{CrossMark}

${ }^{1}$ Univesity of Gondar, Department of Ophthalmology, Gondar, Ethiopia ${ }^{2}$ University of Leicester, Department of Ophthalmology, Leicester, UK

${ }^{3}$ Clinical Research, London School of Hygiene \& Tropical Medicine, London, UK

Correspondence to Dr Mulusew Asferaw; muasf@yahoo.com

\section{ABSTRACT}

Objectives To determine the causes of severe visual impairment and blindness (SVI/BL) among students in schools for the blind in Northwest Ethiopia and to identify preventable and treatable causes.

Method Students attending nine schools for the blind in Northwest Ethiopia were examined and causes assigned using the standard WHO record form for children with blindness and low vision in May and June 2015.

Results 383 students were examined, 357 (93\%) of whom were severely visually impaired or blind $(<6 / 60$ in their better eye). 253 (70.9\%) were aged 16 years or above and $228(63.9 \%)$ were males. 100 students aged $<16$ years were blind and four were SVI, total 104. The major anatomical site of visual loss among those $0-15$ years was cornea/phthisis (47.1\%), usually due to measles and vitamin A deficiency, followed by whole globe (22.1\%), lens (9.6\%) and uvea (8.7\%). Among students aged 16 years and above, corneal/phthisis $(76.3 \%)$ was the major anatomical cause, followed by lens $(6.3 \%)$, whole globe $(4.7 \%)$, uvea (3.6\%) and optic nerve (3.2\%). The leading underlying aetiology among students aged $<16$ years was childhood factors (39.4\%) $(13.5 \%$ measles, $10.6 \%$ vitamin $\mathrm{A}$ deficiency), followed by unknown aetiology (54.8\%), perinatal (2.9\%) and hereditary factors $(2.9 \%)$. In the older group, childhood factors (72.3\%) (25\% measles, $15 \%$ vitamin A deficiency) were major causes, followed by unknown aetiology $(24.1 \%)$, perinatal $(2.4 \%)$ and hereditary factors $(0.8 \%)$. Over $80 \%$ of the causes were avoidable with majority being potentially preventable (65\%).

Conclusion Corneal blindness, mainly as the result of measles and vitamin A deficiency, is still a public health problem in Northwest Ethiopia, and this has not changed as observed in other low-income countries. More than three-fourth of causes of SVI/BL in students in schools for the blind are potentially avoidable, with measles/vitamin A deficiency and cataract being the leading causes.

\section{INTRODUCTION}

The revised 2010 estimate showed that the number of blind children in the world has declined to 1.26 million compared with the previous estimate in 1999 of 1.4 million. However, in Sub-Saharan Africa, the number of blind children has increased by $31 \%$ to $419000 .{ }^{1}$ Children who are blind in this region

\section{Key questions}

What is already known about this subject?

- Corneal scarring has been the leading cause of childhood blindness in low-income countries. However, implementation of programmes to reduce vitamin A deficiency and measles has substantially reduced this cause of blindness with cataract now being the main avoidable cause of blindness in children in many developing countries.

\section{What are the new findings?}

- Corneal scarring mainly due to measles and vitamin A deficiency is still the leading causes of blindness in children in schools for the blind in Northwest Ethiopia.

\section{Recommendations for policy}

- Policy makers need to implement strategies to control childhood blindness from avoidable causes including measles, vitamin A deficiency, cataract and refractive errors.

are likely to have a high mortality, but those who survive contribute a disproportionate number of blind years of disability. Many of the causes of severe visual impairment and blindness (SVI/BL) in children are preventable or treatable, and therefore the control of blindness in children is a high priority in the $\mathrm{WHO}$ and the International Agency for the Prevention of Blindness (IAPB) VISION2020 initiative, the Right to Sight. ${ }^{2}$

There is a marked regional variation in the prevalence and major causes of childhood blindness in different parts of the world, reflecting varying socioeconomic development and under-5 mortality rates. ${ }^{3}$ The prevalence ranges from $0.3 / 1000$ children in high-income countries to $1.5 / 1000$ children in low-income countries. ${ }^{3}{ }^{4}$ In the poorest countries, corneal scarring due to vitamin A deficiency, measles, ophthalmia neonatorum and the use of traditional practices have been a major cause of blindness, but have declined dramatically in many countries as a result of 
Table 1 Presenting visual status of students attending nine schools for the blind in Northwest Ethiopia by sex and age group

\begin{tabular}{|c|c|c|c|c|c|c|c|c|}
\hline \multirow[t]{2}{*}{$\begin{array}{l}\text { WHO category of visual } \\
\text { loss }\end{array}$} & \multirow[t]{2}{*}{$\begin{array}{l}\text { Visual acuity in } \\
\text { better eye }\end{array}$} & \multicolumn{2}{|l|}{ Sex } & \multicolumn{4}{|c|}{ Age category in years } & \multirow{2}{*}{$\begin{array}{l}\text { Total } \\
\text { N (\%) }\end{array}$} \\
\hline & & Male & Female & $6-10$ & 11-15 & $16-20$ & 21-25 & \\
\hline Visual impairment (VI) & $<6 / 18-6 / 60$ & 7 & 10 & 2 & 4 & 8 & 3 & $17(4.4)$ \\
\hline $\begin{array}{l}\text { Severe visual impairment } \\
\text { (SVI) }\end{array}$ & $<6 / 60-3 / 60$ & 10 & 3 & 0 & 4 & 8 & 1 & $13(3.4)$ \\
\hline Blind (BL) & NLP & 85 & 63 & 8 & 26 & 79 & 35 & $148(38.6)$ \\
\hline Total & & 244 & 139 & 22 & 92 & 182 & 87 & $383(100)$ \\
\hline
\end{tabular}

economic development and more extensive programmes of measles immunisation and better control of vitamin A deficiency. In these settings, cataract is now often the most common avoidable cause of blindness. ${ }^{5}$ In many middle-income countries, retinopathy of prematurity has become the most common cause, whereas in high-income countries central nervous system disorders and retinal conditions are the most common causes. ${ }^{5}$

Population-based data on the causes of blindness in children are difficult to obtain, particularly in developing countries like Ethiopia, as registers of the blind do not exist and very large sample sizes are required for formal population-based cross-sectional surveys. Examination of children enrolled in schools for the blind offers the opportunity to examine a large number of children quickly in a standard manner by a few examiners. Over the past 20 years, the WHO classification system, which uses anatomical and aetiological categories of causes and standard recording form, has been increasingly used, which allows data to be compared between studies. $^{6}$

\section{METHODS}

The study was conducted in nine schools providing special education for blind students in North Gondar, South Gondar and Bahirdar City administrative zones, Amhara regional state in Northwest Ethiopia. Eight of the schools were integrated schools and one, in Gondar city, was a special school for the blind. The study was conducted during May and June 2015. All students under the age of 16 years at the time of the study and aged 16 years and above but who became visually impaired before the age of 16 years were included.

A team comprising a paediatric ophthalmologist and two trained optometrists undertook the examinations. A brief history of the eye condition, family history, and the presence of additional impairments (eg, cognitive, physical or hearing impairment and epilepsy) was recorded. Additional relevant information was collected from class teachers and family members. No medical records were available.

Distance visual acuity was measured by the optometrists using a Snellen E chart at 6 and $3 \mathrm{~m}$, testing each eye separately and then with both eyes open, with current spectacles, if available. Students with profound visual loss were assessed for light projection and perception of light. Visual loss was categorised according to the WHO categories of visual impairment. ${ }^{6}$ Visual fields were assessed by confrontation, and intraocular pressures were measured using a Tonopen, a handheld applanation tonometer. Anterior segments were examined using a handheld slit lamp microscope, and posterior segment examination was performed by direct and/or indirect ophthalmoscopy after dilating the pupils with tropicamide $1 \%$ eye drops, when possible. Students who needed refraction had retinoscopy after instillation of cyclopentolate $1 \%$ eye drops. The WHO classification system was used to categorise the cause of SVI/BL using definitions in the coding instructions. One major anatomical site and the relevant underlying cause of vision loss were selected for each eye and then for each student. The needs for optical, surgical or medical interventions were recorded and the visual prognosis assessed. Students requiring further investigations and treatment were referred to the Department of Ophthalmology, Gondar University Hospital. In addition to providing surgical intervention where indicated, low vision aids and spectacles were provided when required.

Data were entered into the WHO childhood blindness software V.1.2.75 and analysed with this software and Microsoft Excel. Data are presented on causes at the level of the child.

Ethical approval was obtained from the Institutional Review Board of the University of Gondar and London School of Hygiene \& Tropical Medicine. Permission to conduct the research was obtained from appropriate government bodies including regional and zonal education offices and schools. Informed consent was obtained from school heads and parents or legal guardians of students in blind schools. Assent was also obtained from students.

\section{RESULTS}

A total of 383 students were examined in the nine schools, $244(63.7 \%)$ of whom were male. Their ages 
Table 2 Anatomical site of abnormality leading to vision impairment in 357 students with SVI/BL in schools for the blind in Northwest Ethiopia by age group

\begin{tabular}{|c|c|c|c|}
\hline Anatomical site & Aged 0-15 years, $n(\%)$ & Aged 16 years and above, $n(\%)$ & Total, n (\%) \\
\hline Whole globe & $23(22.1)$ & $12(4.7)$ & $35(9.8)$ \\
\hline Microphthalmos & $10(9.6)$ & $8(3.2)$ & $18(5.0)$ \\
\hline Anophthalmos & $11(10.6)$ & $4(1.6)$ & $15(4.2)$ \\
\hline Disorganised & $2(1.9)$ & $0(0)$ & $2(0.6)$ \\
\hline Glaucoma/buphthalmos & $2(1.9)$ & $2(0.8)$ & $4(1.1)$ \\
\hline Glaucoma & $2(1.9)$ & $1(0.4)$ & $3(0.8)$ \\
\hline Buphthalmos & $0(0)$ & $1(0.4)$ & $1(0.3)$ \\
\hline Cornea/phthisis & $49(47.1)$ & $193(76.3)$ & $242(67.8)$ \\
\hline Scar & $22(21.1)$ & $83(32.8)$ & $105(29.4)$ \\
\hline Staphyloma & $19(18.3)$ & $55(21.7)$ & $74(20.7)$ \\
\hline Phthisis & $7(6.7)$ & $54(21.3)$ & $61(17.1)$ \\
\hline Keratoconus & $0(0)$ & $1(0.4)$ & $1(0.3)$ \\
\hline Other opacity & $1(0.9)$ & $0(0)$ & $1(0.3)$ \\
\hline Lens & $10(9.6)$ & $16(6.3)$ & $26(7.3)$ \\
\hline Cataract & $7(6.7)$ & $13(5.1)$ & $20(5.6)$ \\
\hline Aphakia/pseudophakia & $3(2.9)$ & $3(1.2)$ & $6(1.7)$ \\
\hline Uvea & $9(8.7)$ & $9(3.6)$ & $18(5.1)$ \\
\hline Uveitis & $3(2.9)$ & $5(2.0)$ & $8(2.2)$ \\
\hline Coloboma & $17(4.8)$ & $2(0.8)$ & $7(2.0)$ \\
\hline Aniridia & $1(0.9)$ & $1(0.4)$ & $1(0.3)$ \\
\hline Other & $0(0)$ & $1(0.4)$ & $1(0.3)$ \\
\hline Retina & $1(0.9)$ & $1(0.4)$ & $2(0.6)$ \\
\hline Dystrophy & $1(0.9)$ & $0(0)$ & $1(0.3)$ \\
\hline Albinism & $0(0)$ & $1(0.4)$ & $1(0.3)$ \\
\hline Optic nerve & $5(4.8)$ & $8(3.2)$ & $13(3.6)$ \\
\hline Atrophy & $5(4.8)$ & $8(3.2)$ & $13(3.6)$ \\
\hline Globe appears normal & $5(4.8)$ & $12(4.7)$ & $17(4.8)$ \\
\hline Refractive error & $2(1.9)$ & $4(1.6)$ & $6(1.9)$ \\
\hline Amblyopia & $2(1.9)$ & $6(2.4)$ & $8(2.2)$ \\
\hline Cortical blindness & $1(0.9)$ & $1(0.4)$ & $2(0.6)$ \\
\hline Idiopathic nystagmus & $0(0)$ & $1(0.4)$ & $1(0.3)$ \\
\hline TOTAL & $104(100)$ & $253(100)$ & $357(100)$ \\
\hline
\end{tabular}

ranged from 6 years to 25 years (mean 17.6 years). One hundred and fourteen $(30 \%)$ students were under the age of 16 years and $269(70 \%)$ were 16 years or above. Additional impairments were identified in nine students $(2.4 \%)$, which included hearing loss in four, cognitive impairment in two, physical handicap in two and epilepsy in one student. In 17 students, there was a positive family history of visual impairment.

Sixteen $(6.7 \%)$ students were not visually impaired or had mild visual impairment and the remainder had severe visual impairment (SVI) $(3.4 \%)$ or were blind (BL) $(89.8 \%$ ) (table 1). Among the 357 students who were SVI/BL, 104 were aged 0-15 years (mean 12.6; range $6-15$ years) and 253 were 16 years or above (mean
19.8; range 16-25 years). Among students aged 0-15 years, there were equal numbers of males and females.

Previous surgical intervention had been performed in 22/383 (5.7\%) students: cataract surgery (9), glaucoma surgery (3), enucleation (6), corneal graft (1), optical iridectomy (1) and tarsotomy (1).

The reported age of onset of visual loss was at birth in $36.5 \%$ of students aged $0-15$ years and $5.9 \%$ among older students aged 16 years and above. Among younger students (under 16 years of age), 38.5\% reported becoming blind before the age of 6 years compared with $34.3 \%$ of older students. Among younger students, $75 \%$ were born blind or became blind before the age of 6 years compared with $40.3 \%$ of older students. 


\begin{tabular}{|c|c|c|c|}
\hline Aetiology & Aged $0-15$ years, $n(\%)$ & Aged 16years and above, $\mathrm{n}(\%)$ & Total, n (\%) \\
\hline Hereditary & $3(2.9)$ & $2(0.8)$ & $5(1.4)$ \\
\hline Autosomal dominant & $3(2.9)$ & $0(0)$ & $3(0.8)$ \\
\hline Autosomal recessive & $0(0)$ & $1(0.4)$ & $1(0.3)$ \\
\hline Unspecified & $0(0)$ & $1(0.4)$ & $1(0.3)$ \\
\hline Intrauterinecongenital rubella syndrome & $0(0)$ & $1(0.4)$ & $1(0.3)$ \\
\hline Perinatal/Neonatal factor & $3(2.9)$ & $6(2.4)$ & $9(2.5)$ \\
\hline Ophthalmia neonatorum & $2(1.9)$ & $6(2.4)$ & $8(2.2)$ \\
\hline Cerebral hypoxia/injury & $1(0.9)$ & $0(0)$ & $1(0.3)$ \\
\hline Postnatal/childhood factor & $41(39.4)$ & $183(72.3)$ & $224(63)$ \\
\hline Measles & 14 (13.5) & $64(25.3)$ & $78(21.8)$ \\
\hline Vitamin A deficiency & $11(10.6)$ & $39(15.4)$ & $50(14.0)$ \\
\hline Other acquired corneal infection/ulcer & $11(10.6)$ & $69(27)$ & $79(22)$ \\
\hline Harmful traditional practice & $1(0.9)$ & $1(0.4)$ & $2(0.6)$ \\
\hline Trauma & $1(0.9)$ & $8(3.2)$ & $9(2.5)$ \\
\hline Neoplasm & $1(0.9)$ & $0(0)$ & $1(0.3)$ \\
\hline Other & $2(12.5)$ & $2(0.8)$ & $5(1.2)$ \\
\hline Unknown aetiology & $57(54.8)$ & $61(24.1)$ & $118(33)$ \\
\hline Abnormality since birth & 35 (33.6) & $17(6.7)$ & $52(14.6)$ \\
\hline Cataract & $8(7.7)$ & $14(5.5)$ & $22(6.2)$ \\
\hline Glaucoma/buphthalmos & $2(1.9)$ & $2(0.8)$ & $4(1.1)$ \\
\hline Other & $12(11.5)$ & $28(11.1)$ & $40(11.2)$ \\
\hline Total & $104(100)$ & $253(100)$ & $357(100)$ \\
\hline
\end{tabular}

\section{ANATOMICAL CAUSES OF SVI/BL}

Overall, corneal disease, mainly scarring, staphyloma and phthisis, was the most frequent site leading to visual loss, accounting for $67.8 \%$ of SVI/BL (table 2). Corneal blindness was more common in older (aged 16 years and above) than younger (under 16 years) students $(76.3 \%$ and $47.1 \%$, respectively). Lesions of the whole globe, including anophthalmos and microphthalmos, were the second most frequent causes accounting for $9.8 \%$ overall, being a more important cause in younger than older students $(22.1 \%$ and $4.7 \%$, respectively). Twenty students $(5.6 \%)$ were SVI/ BL from unoperated cataract and six (1.7\%) were still SVI/BL after cataract surgery, with little difference between age groups. Other sites of abnormality leading to visual loss were relatively uncommon, with little difference between age groups.

\section{AETIOLOGY OF SVI/BL}

Among 357 students with SVI/BL, the aetiology was classified as 'childhood factors' in $63 \%$, with measles, vitamin A deficiency and other corneal infection/ulcer being the leading underlying causes, accounting for $22 \%, 14 \%$ and $22 \%$, respectively (table 3 ). Childhood factors were more common causes in the older (16 years and above) than the younger (under 16 years) age group (72.3\% and $39.4 \%$, respectively). Perinatal factors, mainly ophthalmia neonatorum, were responsible for only $2.5 \%$ of cases and hereditary $(1.4 \%)$ and intrauterine factors $(0.3 \%)$ were also uncommon. No student was SVI/BL from retinopathy of prematurity. A third (33\%) of cases were classified as being of unknown aetiology which included abnormalities present since birth $(15 \%)$, cataract $(6 \%)$, glaucoma $(1 \%)$ and other $(11 \%)$. The other category included optic atrophy $(3.4 \%)$, refractive errors and amblyopia (3.1\%). Unknown aetiology was recorded more commonly in younger than in older students $(55 \%$ and $24 \%$, respectively).

\section{AVOIDABLE CAUSES OF SVI/BL}

Over $80 \%$ of students had potentially avoidable causes of vision loss, with a higher proportion being preventable $(65 \%)$ than treatable $(15.7 \%)$ (table 4$)$. Corneal blindness due to scarring, measles and vitamin A deficiency were the major preventable causes, while cataract, refractive error/amblyopia and uveitis were the major treatable causes. Preventable causes were more common in older (16 years and above) than younger students (74.7\% and $41.3 \%$, respectively), whereas treatable causes were 
Table 4 Avoidable causes among 357 students with SVI/BL in schools for the blind in Northwest Ethiopia by age group

\begin{tabular}{lccc}
\hline Aetiology & Aged 0-15years, $\mathbf{n}(\%)$ & Aged 16 years and above, $\mathbf{n}(\%)$ & Total, $\mathbf{n}(\%)$ \\
\hline Preventable conditions & & & \\
\hline Corneal scarring & $11(10.6)$ & $69(27.3)$ & $80(22.4)$ \\
\hline Measles & $14(13.5)$ & $64(25.3)$ & $78(21.8)$ \\
\hline Vitamin A deficiency & $11(10.6)$ & $39(15.4)$ & $50(14)$ \\
\hline Trauma & $1(1.0)$ & $8(3.2)$ & $9(2.5)$ \\
\hline Ophthalmia neonatorum & $2(1.9)$ & $6(2.4)$ & $8(2.2)$ \\
\hline Harmful traditional practice & $1(1.0)$ & $1(0.4)$ & $2(0.6)$ \\
\hline Autosomal dominant & $2(1.9)$ & $0(0)$ & $2(0.6)$ \\
\hline Rubella & $0(0)$ & $1(0.4)$ & $1(0.3)$ \\
\hline Trachoma & $0(0)$ & $1(0.4)$ & $1(0.3)$ \\
\hline Cerebral hyopxia/injury & $1(1.0)$ & $0(0)$ & $1(0.3)$ \\
\hline Subtotal & $\mathbf{4 3 ( 4 1 . 3 )}$ & $\mathbf{1 8 9 ( 7 4 . 7 )}$ & $\mathbf{2 3 2}(\mathbf{6 5 . 0 )}$ \\
\hline Treatable conditions & & & $22(6.2)$ \\
\hline Cataract & $8(7.7)$ & $14(5.5)$ & $8(2.2)$ \\
\hline Uveitis & $3(2.9)$ & $5(2.0)$ & $6(1.7)$ \\
\hline Refractive error & $2(1.9)$ & $4(1.6)$ & $8(2.2)$ \\
\hline Refractive amblyopia & $2(1.9)$ & $6(2.4)$ & $4(1.1)$ \\
\hline Glaucoma & $2(1.9)$ & $2(0.9)$ & $4(1.1)$ \\
\hline Corneal scar & $2(1.9)$ & $2(0.9)$ & $2(0.6)$ \\
\hline Vernal keratoconjunctivitis & $2(1.9)$ & $0(0)$ & $1(0.3)$ \\
\hline Keratoconus & $0(0)$ & $1(0.4)$ & $1(0.3)$ \\
\hline Brain tumour & $1(1.0)$ & $0(0)$ & $\mathbf{5 6}(\mathbf{1 5 . 7 )}$ \\
\hline Subtotal & $\mathbf{2 2 ( 2 1 . 1 )}$ & $\mathbf{3 4}(\mathbf{1 3 . 4})$ & $\mathbf{8 0 . 7 )}$ \\
\hline Total avoidable & $\mathbf{6 5 ( 6 2 . 5 )}$ & $\mathbf{2 2 3 ( 8 8 . 1 )}$ & \\
\hline
\end{tabular}

relatively more common in younger students (under 16 years).

\section{TRENDS IN SVI/BL OVER TIME}

To determine possible trends on the pattern of major causes of visual loss, students with SVI/BL were grouped into four age groups: (a) age 6-10 years $(\mathrm{n}=19)$, (b) 11-15 years $(n=85)$, (c) 16-20 years $(n=169)$ and $(d) 21-25$ years $(n=84)$ (figure $1 \mathrm{~A}$ and $\mathrm{B})$. Corneal pathologies were the leading cause of SVI/BL in the oldest three groups (b, c, d), while whole globe was the leading cause in the youngest (a) (figure 1A). The change in aetiology with age reflects these differences with acquired conditions of childhood predominating in the older two age groups (c, d), with an unknown aetiology being more common in the younger two age groups (a, b) (figure 1B). Among childhood factors, measles and vitamin A deficiency were analysed separately. Vitamin A deficiency was responsible for visual loss in $9.5 \%$ in students aged 21-25 years, $18.3 \%$ in students aged $16-20$ years, $11.8 \%$ in students aged $11-15$ years and $5.3 \%$ in students aged $6-10$ years, whereas measles was responsible in $23.8 \%, 26.0 \%, 15.3 \%$ and $5.3 \%$ in the same age groups.
The date of onset of visual loss, as recalled by students, was also recorded which allowed the approximate year of onset to be determined. Causes of vision loss were grouped as corneal and non-corneal (figure 2). Corneal blindness was responsible for approximately half of all vision loss for each estimated year of onset.

\section{TREATIMENT AND PROGNOSIS}

No intervention was needed for most students as they were irreversibly blind. Vision could be improved in 20 right eyes $(5.2 \%)$ and in 29 left eyes $(7.6 \%)$. Visual acuity was expected to deteriorate in $13(3.4 \%)$ right eyes and $11(2.9 \%)$ left eyes. Spectacle prescription was recommended in 22, low vision devices in 13 and surgical intervention, principally cataract surgery and corneal transplantation, was recommended in 33 students. A change in school was recommended for 10 students.

\section{DISCUSSION}

In this study, the majority of students $(93 \%)$ attending special education were SVI/BL, being similar to the previous study in Ethiopia ${ }^{7}$ and in Burundi. ${ }^{8}$ In our study, 

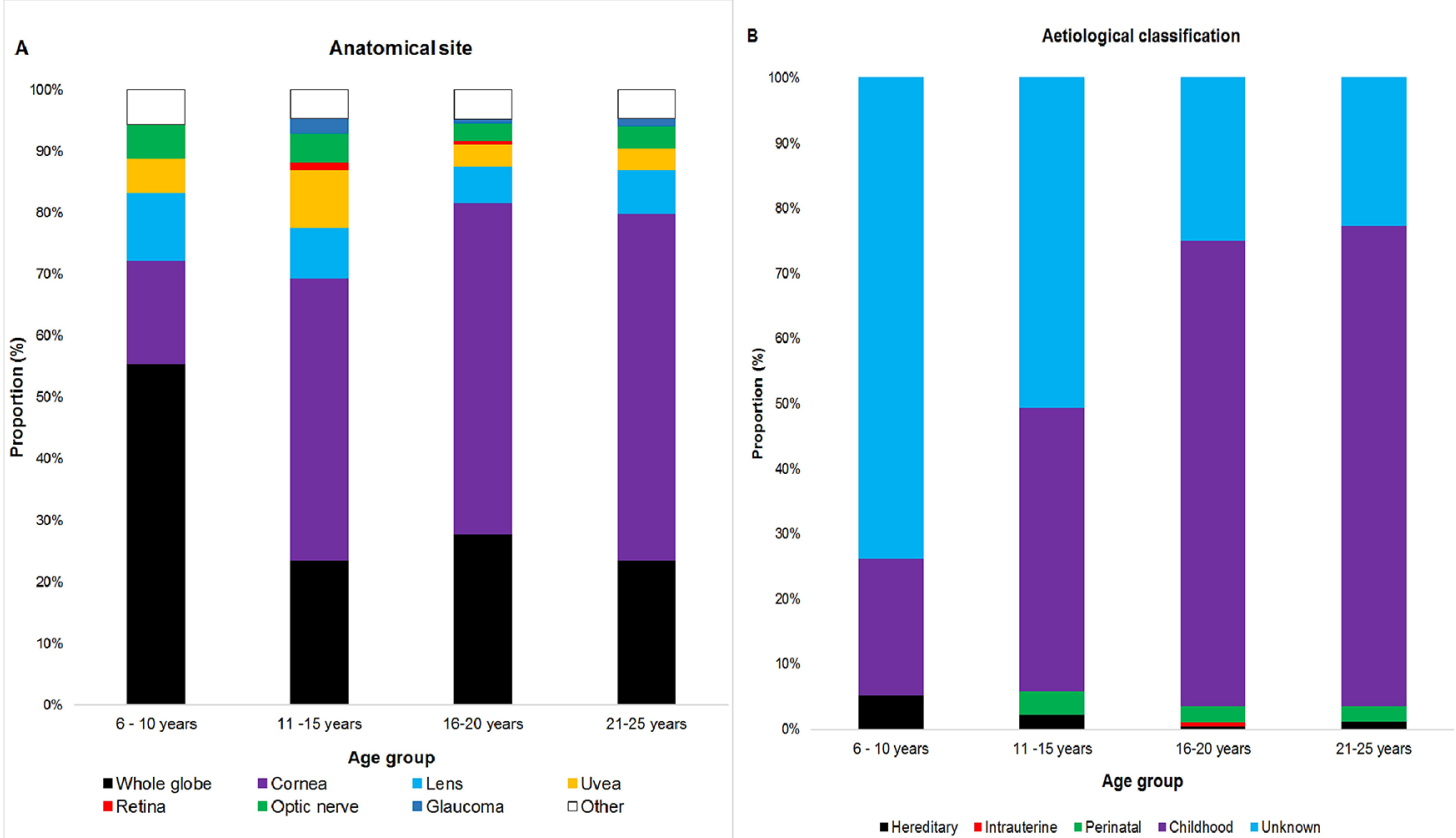

Figure 1 Anatomical site $(A)$ and aetiological category $(B)$ of principal abnormality in students of different age groups.

there were nine students $(2.3 \%)$ who had visual acuity of $6 / 18$ or better who were inappropriately enrolled in schools for the blind, although the proportion of students with good visual acuity was lower than in some studies. ${ }^{9}$

In our study, only $30 \%$ of students were younger than 16 years, and similar findings have been reported in two studies in Nigeria ${ }^{10}{ }^{11}$ where $65 \%$ were 16 years or above, and one study in Burundi ${ }^{8}$ where almost half the students were older than 15 years. The attendance of young adults in schools for the blind may indicate that once a child enters a blind school they tend to stay there, often because of poor academic attainment for several reasons: they often start school very late and miss a lot of schooling, Braille educational materials are often limited, and so students find it harder to learn and reach the level required to progress. In addition, children with SVI/BL may be abandoned by their carers particularly if they are admitted to residential schools. Further studies on the role and impact of education in schools for the blind in Africa are needed.

Two-thirds of all students in our study had vision loss from corneal scarring or phthisis, which affected almost half of the students under the age of 16 years. This is essentially the same as in the study carried out in Ethiopian schools for the blind 15 years ago in which $62.4 \%$ of children aged less than 16 years were SVI/BL from corneal scarring or phthisis ${ }^{7}$ but is considerably higher than in other studies in Africa for example, in Burundi $(24 \%),{ }^{8}$ Oyo State in Nigeria $(29 \%),{ }^{10}$ Cameroon $(32 \%)^{12}$ and East Africa $(19 \%) .{ }^{13}$ In contrast, corneal scarring/

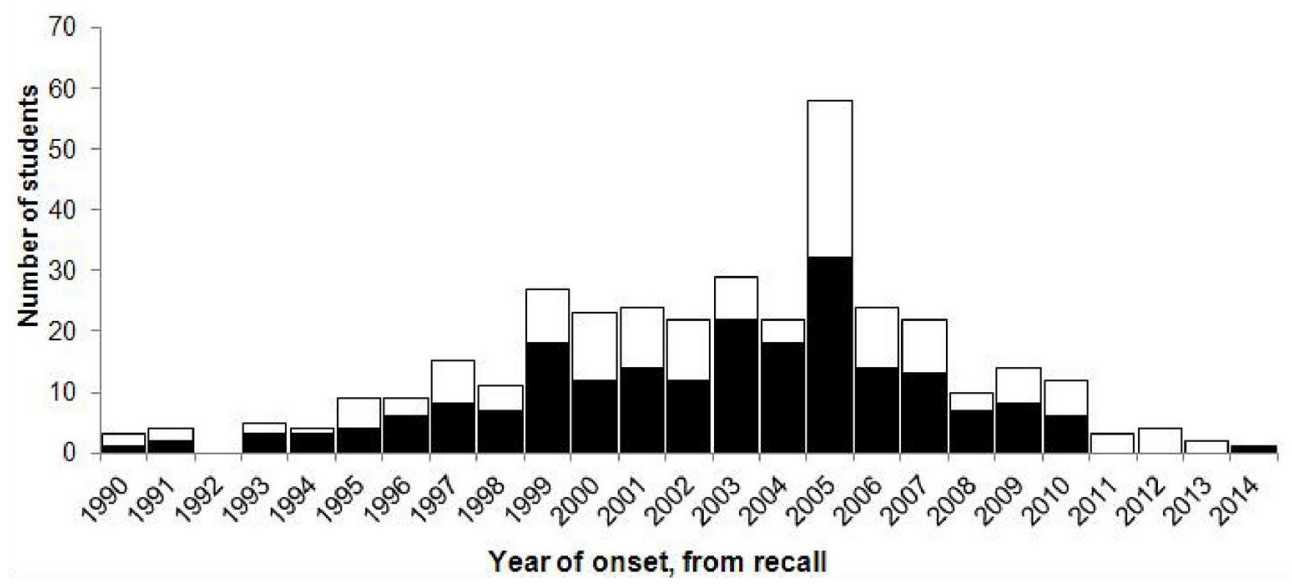

Figure 2 Recollected date of onset of visual loss of students with severe visual impairment and blindness. 
phthisis was not the main anatomical site in South Eastern Nigeria $^{11}$ and Uganda, ${ }^{14}$ being responsible for $21 \%$ of visual loss. Lens pathology was the leading anatomical site of vision loss in South Eastern Nigeria $(31.4 \%)$ and globe pathology (27\%) in Uganda. Our findings are similar to a study in 1993 in Zimbabwe in which $67 \%$ of children were blind from corneal pathology. ${ }^{15}$

Recent studies in poor countries in south east Asia have shown a lower proportion of SVI/BL due to corneal scarring than in Africa, ${ }^{16-18}$ ranging from $5 \%$ in Bhutan $^{16}$ to $8 \%$ in South India. ${ }^{19}$

Data on the underlying aetiology need to be interpreted with caution, as medical records were not available and the diagnosis was made on the clinical appearance, or what students reported.

In our study, a quarter of students were identified as having had measles or vitamin A deficiency as the principal underlying cause of their vision loss, being similar to recent studies from Asia and Africa. However, a further $10.6 \%$ had corneal scarring where an underlying cause could not be determined, where vitamin A deficiency may have contributed to the corneal pathology, so underestimating the relative contribution. Despite an improvement in measles immunisation coverage from $59 \%$ in 2005 to $84 \%$ in 2014 , the incidence of measles infection increased from 0.6 per 100,000 in 2005 to 11.1 per 100,000 in $2014 .^{20}$ According to the 2011 Ethiopian Demographic and Health Survey (DHS), measles immunisation coverage was only $56 \%$ overall, with significant variation between regions. ${ }^{21}$ Vitamin A deficiency is also a serious public health problem in Ethiopia with a national prevalence of Bitot's spots of 1.7\% among children aged 6-71 months, and $37.7 \%$ of children had deficient serum retinol levels. In this study, only $22.6 \%$ of children had received a vitamin A supplement in the previous 6 months. ${ }^{22}$ Data from the 2011 DHS also showed that coverage of vitamin A supplementation in the previous 6 months among children aged 6-59 months was suboptimal $(54.5 \%$ overall) with regional differences ranging from $28 \%$ to $83 \%{ }^{23}$ Children in the poorest households, or whose mothers did not attend antenatal or postnatal care or where the mother had not worked during the previous year had the lowest coverage.

In our study, $7.7 \%$ of children under 16 years and $6.2 \%$ of all students had cataract as the principal diagnosis, but only one-third had undergone cataract surgery. Eighteen per cent of children attending schools for the blind in Kenya, Malawi, Tanzania and Uganda had cataract as the major cause of visual impairment, with $83 \%$ of these having had surgery in at least one eye. ${ }^{24}$ The lower proportion of cataract blindness in our study almost certainly reflects the larger number of children with corneal pathology.

The number of students in our study, although large, represents only a small minority of the estimated number of young people with SVI/BL in Northwest Ethiopia, which is likely to be approximately 8749 , assuming a prevalence of 1/1000 children. Children in schools for the blind may, therefore, not be representative of blind children in the whole population as preschool age children and those with additional impairments, such as cerebral palsy, are likely to be under-represented. In addition, children from remote and underserved parts of the country may not attend a special school.

Data in this study were collected using the WHO classification and Coding Instructions. This has the advantage of allowing comparison to be made with other studies but major difficulties remain in identifying the underlying aetiology many years after the onset of disease. There were no medical records in any school and relying on the response of students is likely to lead to bias. This is one of the limitations of this study.

There is inconsistency in the literature regarding how to classify phthisis bulbi, which in low-income settings is often secondary to corneal perforation. In this study, the WHO guidelines were strictly followed and phthisis was classified under corneal pathology rather than whole globe.

It is difficult to assess trends over time in the aetiology of SVI/BL in this study for several reasons. First, student's recall of the age of onset of their visual loss is likely to be unreliable, and second, children who stay on at school may be different from those who leave at the usual age, so introducing bias. However, it was noted that there was a trend of reduction of measles as the cause of visual loss but there does not seem to be a change in pattern of vitamin A deficiency.

\section{CONCLUSIONS AND IMPLICATIONS}

Corneal blindness, mainly as the result of measles and vitamin A deficiency, is still a public health problem in Northwest Ethiopia, and this has not changed over time as has been observed in other low-income countries. More than three-quarters of the causes of SVI/BL are potentially avoidable, with measles, vitamin A deficiency and cataract being the leading causes.

Concerted and integrated efforts are needed by the Ministry of Health and other authorities, primary healthcare workers, eye care professionals and educators to implement primary healthcare to prevent corneal blindness from vitamin A deficiency and measles and to increase the detection, referral and management of cataract and refractive error. Initiatives to improve coverage of measles immunisation and enhance vitamin A supplementation are also urgently needed, both of which will reduce under-5 mortality rates as well as vision loss and blindness in children. The WHO recommends one tertiary level child eye health facility per 10 million population, ${ }^{24}$ but currently there are only three for a population of over 90 million in Ethiopia. Strengthening existing facilities and establishing new centres so that there is one in each region of the country are highly recommended to address the treatable causes of childhood blindness. 
Acknowledgements The authors wish to thank The British Council for the Prevention of Blindness (BCPB) for funding this study and participant students, school teachers, authorities in education offices of respective zones for their participation and help during data collection. Our heartfelt thanks to Mr Sisay Addisie, the late project co-ordinator, Department of Ophthalmology of Gondar, for his kind support and facilitation of logistics during the fieldwork.

Contributors MA, GW and CG conceived of the study. MA collected the data. MA, GW and CG analysed the data. All the authors contributed to the manuscript and approved the final draft for submission.

Competing interests None delared.

Patient consent Obtained.

Ethics approval IRB of University of Gondar and London School of Hygiene and Tropical Medicine.

Provenance and peer review Not commissioned; externally peer reviewed.

Data sharing statement No additional data are available.

Open Access This is an Open Access article distributed in accordance with the Creative Commons Attribution Non Commercial (CC BY-NC 4.0) license, which permits others to distribute, remix, adapt, build upon this work non-commercially, and license their derivative works on different terms, provided the original work is properly cited and the use is non-commercial. See: http://creativecommons.org/ licenses/by-nc/4.0/

(c) Article author(s) (or their employer(s) unless otherwise stated in the text of the article) 2017. All rights reserved. No commercial use is permitted unless otherwise expressly granted.

\section{REFERENCES}

1. Chandna A, Gilbert C. When your eye patient is a child. Community Eye Health 2010;23:1-3.

2. WHO. Preventing blindness in children: report of a WHO/IAPB scientific meeting, Hyderabad, India, 13-17 April 1999: World Health Organization Geneva, 2000. WHO/PBL/00.77.

3. Gilbert CE, Anderton L, Dandona L, et al. Prevalence of visual impairment in children: a review of available data. Ophthalmic Epidemiol 1999;6:73-82.

4. Gilbert C, Foster A. Childhood blindness in the context of VISION 2020--the right to sight. Bull World Health Organ 2001;79:227-32.

5. Parikshit G, Clare G. Blindness in children: a worldwide perspective. Community Eye Health 2007;20:32-3.

6. Gilbert C, Foster A, Negrel AD, et al. Childhood blindness: a new form for recording causes of visual loss in children. Bull World Health Organ 1993;71:485-9.

7. Kello AB, Gilbert C. Causes of severe visual impairment and blindness in children in schools for the blind in Ethiopia. $\mathrm{Br} J$ Ophthalmol 2003;87:526-30.
8. Ruhagaze P, Njuguna KK, Kandeke L, et al. Blindness and severe visual impairment in pupils at schools for the blind in Burundi. Middle East Afr J Ophthalmol 2013;20:61-5.

9. Tumwesigye C, Msukwa G, Njuguna M, et al. Inappropriate enrollment of children in schools for the visually impaired in east Africa. Ann Trop Paediatr 2009;29:135-9.

10. Mosuro AL, Ajaiyeoba Al, Bekibele CO, et al. Survey of low vision among students attending schools for the blind in Nigeria: a descriptive and interventional study. Middle East Afr J Ophthalmol 2012;19:382- 91.

11. Ezegwui IR, Umeh RE, Ezepue UF. Causes of childhood blindness: results from schools for the blind in south eastern Nigeria. $\mathrm{Br} J$ Ophthalmol 2003;87:20-3.

12. Noche CD, Bella AL. [Frequency and causes of blindness and visual impairment in schools for the blind in Yaoundé (Cameroon)]. Sante 2010;20:133-8.

13. Njuguna M, Msukwa G, Shilio B, et al. Causes of severe visual impairment and blindness in children in schools for the blind in Eastern Africa: changes in the last 14 years. Ophthalmic Epidemiol 2009;16:151-5.

14. Watmon B, Nyathirombo A. Causes of severe visual impairment and blindness in the schools for the blind in the Northern and North Western Uganda. JOECSA 2013;17:6-9.

15. Schwab L, Kagame K. Blindness in Africa: Zimbabwe schools for the blind survey. Br J Ophthalmol 1993;77:410-2.

16. Farmer LD, Ng SK, Rudkin A, et al. Causes of severe visual impairment and blindness: comparative data from Bhutanese and Laotian schools for the blind. Asia Pac J Ophthalmol 2015;4:350- 6.

17. Muhit MA, Shah SP, Gilbert CE, et al. Causes of severe visual impairment and blindness in Bangladesh: a study of 1935 children. Br J Ophthalmol 2007;91:1000-4.

18. Kong L, Fry M, Al-Samarraie M, et al. An update on progress and the changing epidemiology of causes of childhood blindness worldwide. $J$ AAPOS 2012;16:501-7.

19. Krishnaiah S, Subba Rao B, Lakshmi Narasamma K, et al. A survey of severe visual impairment in children attending schools for the blind in a coastal district of Andhra Pradesh in South India. Eye 2012;26:1065-70.

20. Federal Ministry of Health. Ethiopia National expanded programme on immunization. Comprehensive multi-year plan 2016-2020. FMOE Addis Ababa: Federal Ministry of Health, 2015.

21. Lakew $Y$, Bekele A, Biadgilign S. Factors influencing full immunization coverage among 12-23 months of age children in Ethiopia: evidence from the national demographic and health survey in 2011. BMC Public Health 2015;15:728.

22. Demissie T, Ali A, Mekonen $Y$, et al. Magnitude and distribution of vitamin A deficiency in Ethiopia. Food Nutr Bull 2010;31:234-41.

23. Haile D, Biadgilign S, Azage M. Differentials in vitamin A supplementation among preschool-aged children in Ethiopia: evidence from the 2011 Ethiopian Demographic and Health Survey. Public Health 2015;129:748-54.

24. Msukwa G, Njuguna M, Tumwesigye C, et al. Cataract in children attending schools for the blind and resource centers in Eastern Africa. Ophthalmology 2009;116:1009-12. 